\title{
Laboratory Flow Tests of Fixed Spray Nozzles with Hydrocarbons and with Air
}

\begin{abstract}
By M. R. Shafer and H. L. Bovey
The metering characteristics of fixed spray nozzles of the type used in some turbo-jet engines have been investigated. Some of the nozzles supplied by the Navy Department contained burrs, metal particles, and improper machining, which caused erratic fluid metering. After being reconditioned, a group of 26 nozzles was flow-tested with five different fluids to determine the effects of fluid density, viscosity, and supply pressure upon the rate of discharge of the nozzles. The results indicate that it is impracticable to correct for differences in the physical properties of the test fluid. A comparative method of flowtesting fixed nozzles with air is described. Although this method leaves much to be desired, it appears useful for safe and rapid sizing of nozzles to within \pm 3 percent of their actual flow.
\end{abstract}

\section{Introduction}

For several years the Bureau of Aeronautics, Department of the Navy, has sponsored at the National Bureau of Standards a program of testing and research on devices for handling and metering fuels for aircraft. A recent phase of this program is concerned with the flow characteristics of fixed spray nozzles of the type that have been used in some turbo-jet engines. Depending upon the supplier, these may be designated as Monarch nozzles, Hago nozzles, etc., and for the present purpose all are essentially alike.

For the present work, three sets of sixty nozzles each were procured. Each set bore a color designation indicating that all of the nozzles of each set had been matched in flow to within \pm 2.5 percent at a pressure of $100 \mathrm{lb} / \mathrm{in}^{2}$

As a first step, all nozzles were flow-tested as received with Varsol at five different pressures. It was found that a large proportion exhibited significant changes in flow characteristics before and after being tested at a pressure of $250 \mathrm{lb} / \mathrm{in}^{2}$ Subsequent disassembly showed that these changes were caused by burrs, metal particles, and poor machining.

From the lot of 180 nozzles, 26 were selected, cleaned, reconditioned, and assembled for use in the remainder of the tests. The flow characteristics of the 26 have remained constant over several months. In order to study the effects of the density and viscosity of the test fluid, they have been tested repeatedly over the pressure range of 5 to $250 \mathrm{lb} / \mathrm{in}^{2}{ }^{2}$ with the following liquid hydrocarbons: Varsol, pure $n$-heptane, Apco-467 oil, a commercial mixture of isooctanes, and Soltrol-100.

In addition, an attempt has been made to develop a method using air, instead of a flammable hydrocarbon, as the test fluid. This report presents the results that have been obtained to date with the six different test media.

\section{Description of Nozzles}

As shown in figure 1, the nozzles consist essentially of a body, an insert, and a strainer. They are designated by Navy Parts List No. 14G320-4.

After passing through the strainer, the fuel is directed by tangential slits in the insert into the swirl chamber formed between the end of the insert and the body. The kinetic energy of the fuel in the swirl chamber is effective in atomizing it as it escapes through the orifice in the body. The dimensions and relative locations of the tangential slits, the swirl chamber, and the orifice determine the pressure-flow characteristics, the spray angle and distribution, and the drizzle point of the nozzle. The latter may be defined as the lowest fuel pressure at which the nozzle produces 
a spray, and below which it discharges large drops or a stream of fuel.

\section{Flow Tests with Varsol of 180 Nozzles as Received}

Figure 2 is a diagram of the apparatus used for flow-testing the three sets of 60 nozzles each, as they were received. The Varsol was circulated by a pump through a low-pressure circuit from a storage tank, through a heat exchanger, and back to the tank at a constant rate of about $200 \mathrm{gal} / \mathrm{hr}$. Fuel to the nozzle was bled from this line, and passed through a Rotameter to a second pump having appropriate valves in a by-pass and in the discharge line. From this pump the Varsol passed through a 10-micron filter to the fitting bearing the nozzle. Fuel pressure was measured at this fitting.

The Rotameter was calibrated with the fluid used for the tests and at the temperature of the tests. Observed values of flow are believed accurate to within at least \pm 0.25 percent. The pressure gages were also calibrated at intervals and are believed to be accurate to within \pm 0.5 $\mathrm{lb} / \mathrm{in}^{2}{ }^{2}$ over the range from 98 to $250 \mathrm{lb} / \mathrm{in}^{2}$.
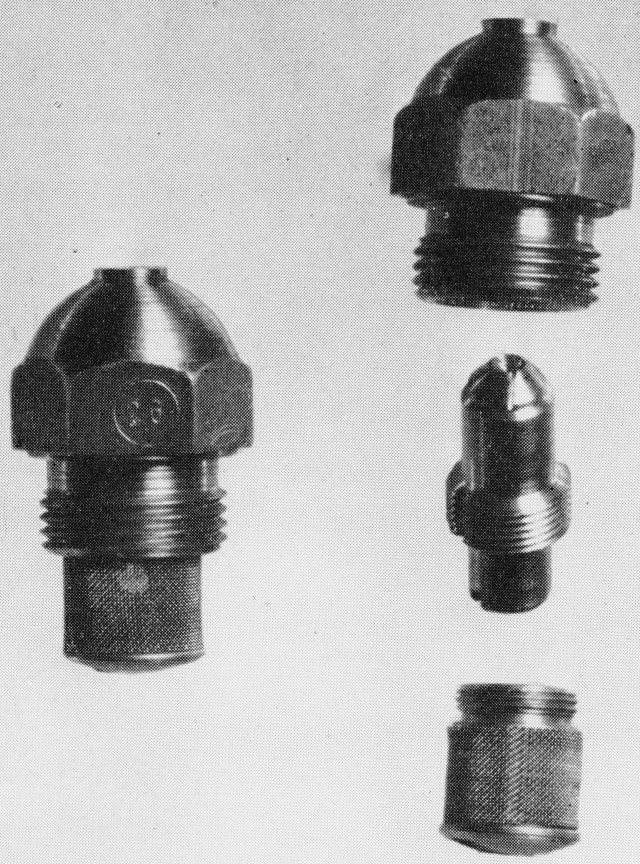

Figure 1. Spray nozzle, parts list No. 14G320-4.
The 180 nozzles were tested as received with Varsol having a kinematic viscosity of 1.102 centistokes and a specific gravity of 0.779 at the test temperature of $80^{\circ} \mathrm{F}$. The flow of each was measured at the following pressures and in the order stated: $98,150,250,50,98$, and $5 \mathrm{lb} / \mathrm{in}^{2}{ }^{2}$ gage. The results, except for the initial values at $98 \mathrm{lb} / \mathrm{in}^{2}{ }^{2}$, are shown in figures 3,4 , and 5 for the sets of 60 nozzles color-coded red, green, and purple, respectively. The flows shown at 98 $\mathrm{lb} / \mathrm{in}^{2}$ were observed after the nozzle had been subjected once to the higher pressures.

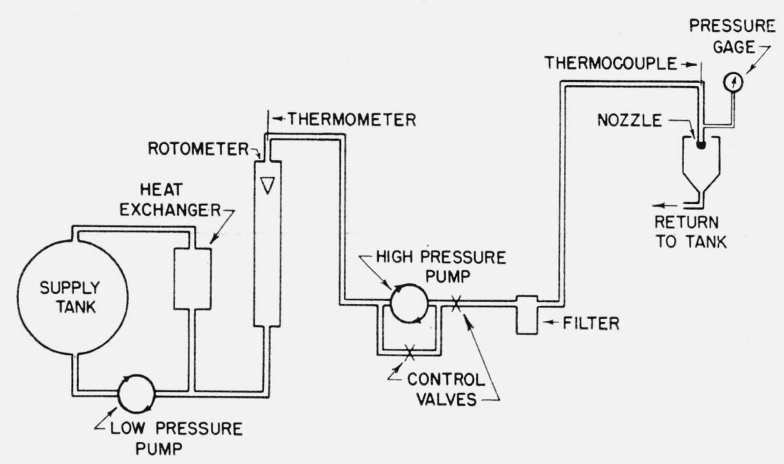

Figure 2. Schematic diagram of nozzle fuel test.
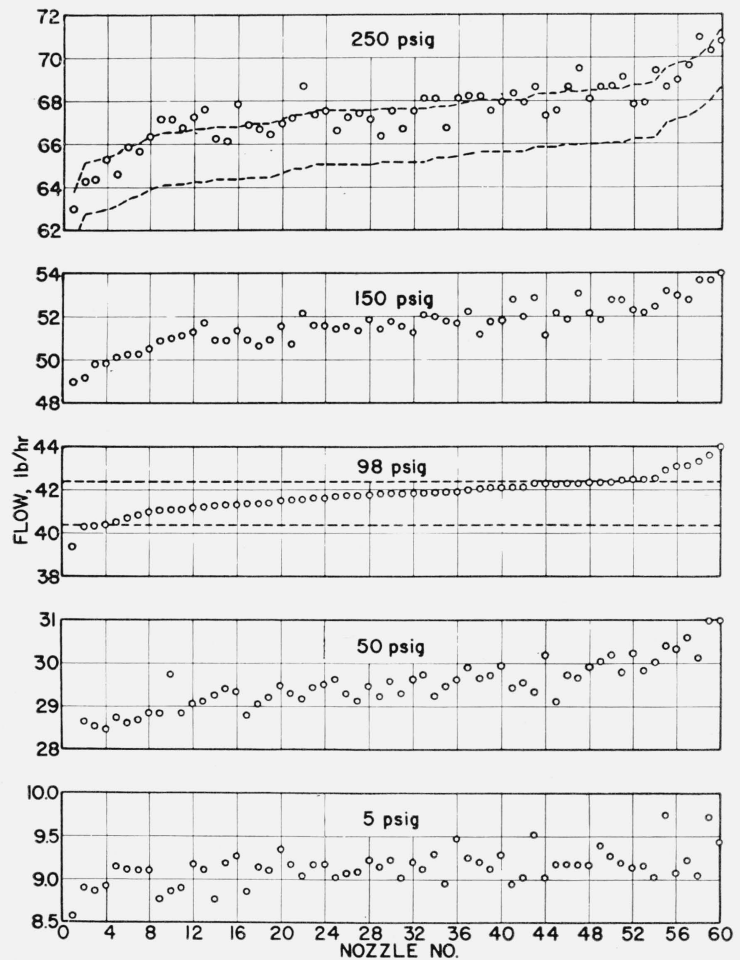

Figure 3. Flow test of 60 red nozzles with Varsol. 

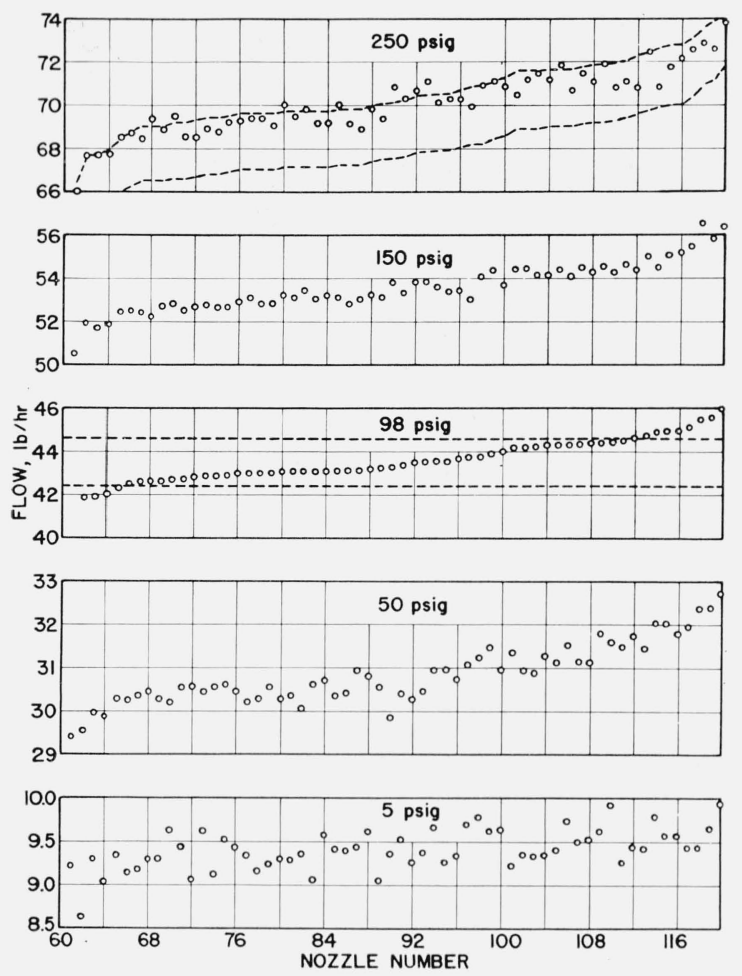

Figure 4. Flow test of 60 green nozzles with Varsol.
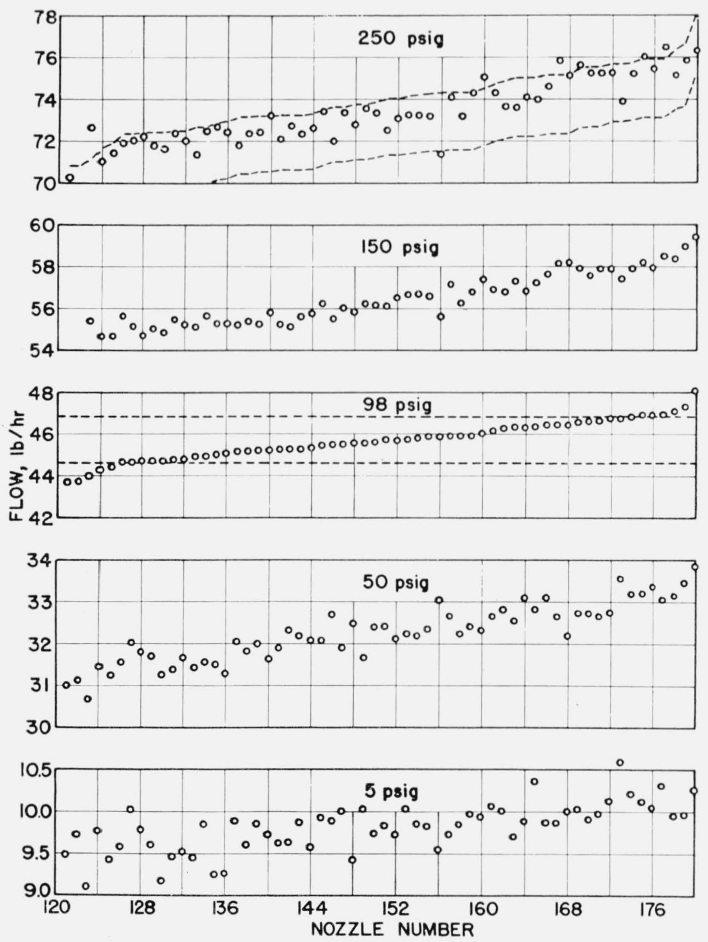

Figure 5. Flow test of 60 purple nozzles with Varsol.
Specifications for these nozzles state that the flow at $250 \mathrm{lb} / \mathrm{in}^{2}$ shall be in the range from 154 to 160 percent of the flow at $100 \mathrm{lb} / \mathrm{in}^{2}$. Correcting these limits to the pressure of $98 \mathrm{lb} / \mathrm{in}^{2}{ }^{2}$ used in the present tests, the limits become 156 and 162 percent of the flow at the test pressure. Specified flow limits for these nozzles at 98 and 250 $\mathrm{lb} /$ in. $^{2}$ are indicated by dashed lines.

It will be noted that some of the nozzles failed to flow within the specified limits, particularly the red group (fig. 3) at $250 \mathrm{lb} / \mathrm{in}^{2}{ }^{2}$ It is also apparent that nozzles that are matched in flow at one pressure frequently are unmatched at other pressures.

Many of the nozzles flowed differently at 98 $\mathrm{lb} / \mathrm{in}^{2}{ }^{2}$ before and after being subjected to higher pressures. As will be seen in figure 6 , this change continued for many pressure cycles with certain nozzles. The zero lines represent the flows at $98 \mathrm{lb} /$ in. $^{2}$ shown in the previous three figures. Flows at this pressure changed by more than 1 percent for 46 of the nozzles as a result of subjecting them to pressure cycling. This indicated that something must have been moved about within the nozzles during the tests.
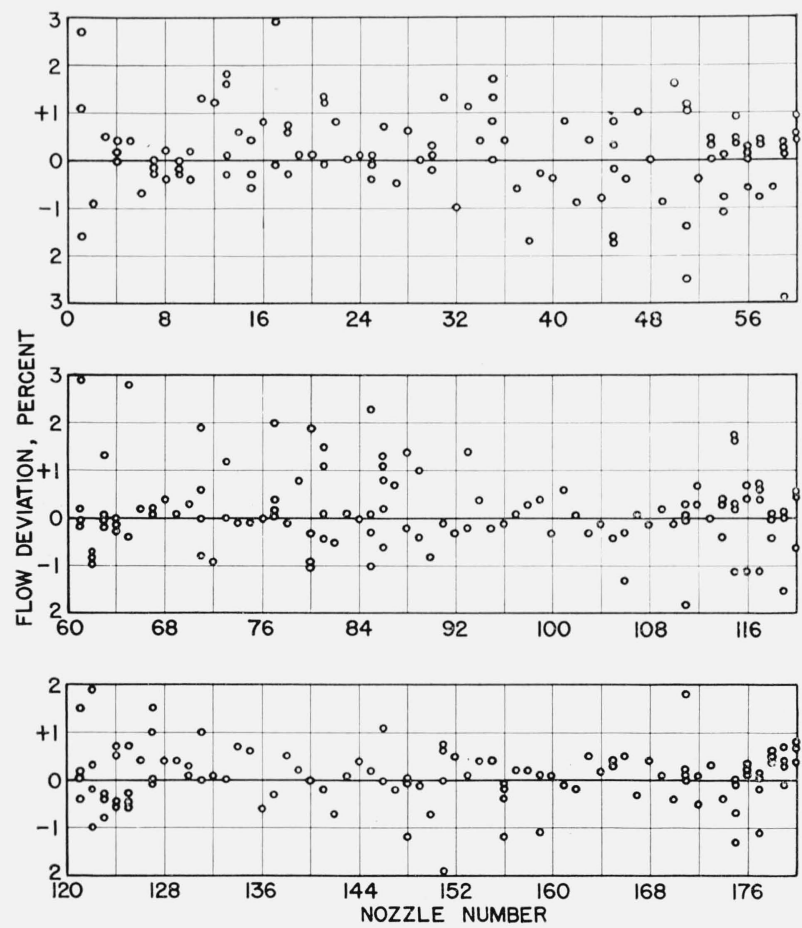

Figure 6. Nozzle flow reproducibility with Varsol at 98 psig as received. 


\section{Reconditioning of 26 Nozzles}

Following the above tests 26 of the nozzles were taken apart, and the following defects were found in all to varying extents:

1. There were metal chips resembling filings in the tangential slits and swirl chambers; 2. Many of the seals between inserts and bodies seemed imperfect; 3 . Most of the inserts were not properly finished on the sealing end, and the edges of the slits were ragged; 4. Large burrs left in cutting the slits remained attached and caused partial blocking of the swirl chambers.

In the enlarged photograph shown in figure 7 such burrs are visible, as are the rough surface of the insert and the ragged edges of the slits.

The burrs and chips were removed, and each nozzle was reassembled with its original insert and strainer. No significant change in flow has occurred subsequently, so that it seems safe to state that initial changes were due to movements of burrs and chips by the test fluid. It is obvious that the presence of such foreign particles cannot be tolerated in a metering device.

\section{Flow Tests of 26 Reconditioned Nozzles with Hydrocarbons}

The 26 reconditioned nozzles, renumbered in the order of increasing flow capacity with Varsol at 98 $\mathrm{lb} / \mathrm{in}^{2}{ }^{2}$, were next flow-tested at pressures of 98 and $250 \mathrm{lb} / \mathrm{in} .{ }^{2}$ with five different hydrocarbons having the following properties:

\begin{tabular}{|c|c|c|c|c|c|}
\hline \multirow{2}{*}{$\begin{array}{l}\text { Test } \\
\text { fluid } \\
\text { No. }\end{array}$} & \multirow{2}{*}{ Name } & \multirow{2}{*}{$\begin{array}{l}\text { Test } \\
\text { tem- } \\
\text { per- } \\
\text { ature }\end{array}$} & \multicolumn{2}{|c|}{$\begin{array}{c}\text { Properties at test } \\
\text { temperature }\end{array}$} & \multirow{2}{*}{$\begin{array}{l}\text { Equiv- } \\
\text { alent } \\
\text { sp.gr. at } \\
60^{\circ} / 60^{\circ} \mathrm{F}\end{array}$} \\
\hline & & & Sp. g. & $\begin{array}{l}\text { Kine- } \\
\text { matic } \\
\text { viscosity }\end{array}$ & \\
\hline & & ${ }^{\circ} F$ & & $\begin{array}{l}\text { Centi- } \\
\text { stokes }\end{array}$ & \\
\hline 1 & Varsol & 80 & 0.779 & 1. 102 & 0.787 \\
\hline 2 & ASTM $n$-Heptane...... & 80 & .679 & .566 & .689 \\
\hline 3 & Apco-467 & 80 & .802 & 2. 282 & .810 \\
\hline 4 & Commercial isooctanes ... & 70 & .743 & .747 & .747 \\
\hline 5 & Soltrol-100 & 75 & .743 & 1.435 & .750 \\
\hline
\end{tabular}

a Values in this column obtained by the aid of table 3 in NBS Circular $\mathrm{C} 410$.

Test fluid No. 1, designated as Varsol, is a general utility solvent, stocked as a storeroom item at this Bureau. It is similar to cleaner's naphtha, made by many companies.

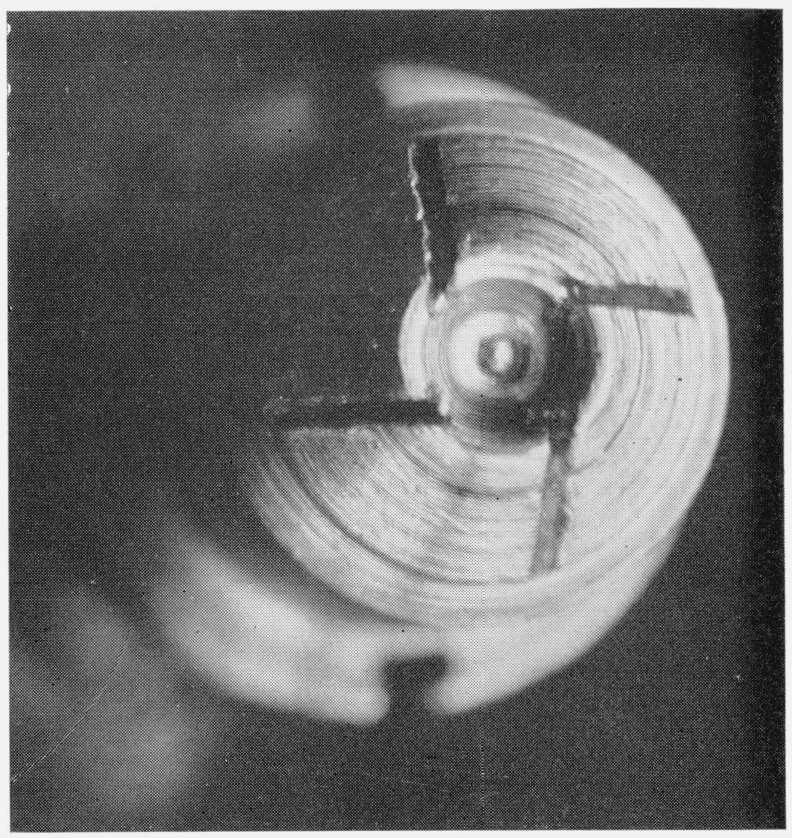

Figure 7. Defective nozzle insert.

Test fluids No. 2, 4, and 5 were supplied through the courtesy of the Phillips Petroleum Co., and test fluid No. 3 through the courtesy of the Anderson-Prichard Oil Corp.

Fluids No. 1,2, and 3 were selected because each is thought to be under consideration as a standard fluid for testing jet engine auxiliaries. Fluids No. 4 and 5 were selected because they have the same density but widely different viscosities. Of the five, $n$-heptane and the mixture of isooctanes have properties approximating those of aviation gasoline, whereas Varsol and Apco resemble kerosene more closely.

The results obtained with 26 nozzles at pressures of 98 and $250 \mathrm{lb} / \mathrm{in} .{ }^{2}$ for each of the five liquid hydrocarbons are presented in table 1 .

Figure 8 is presented to show the reproducibility of the flow measurements and of the nozzles subsequent to reconditioning. Each point represents the deviation of one observation made with Varsol from the average of all observations made with the same nozzle, fluid, and test pressure. The maximum deviation does not exceed \pm 0.5 percent, and only 5 of 100 observations deviate from the mean by more than \pm 0.25 percent. Thus the nozzles themselves, as well as the measurements, appear satisfactory for present purposes.

The changes effected by reconditioning the nozzles are shown in figure 9. As will be seen, 
TABLE 1. Flow capacity (pounds per hour) of 26 nozzles for 5 liquid hydrocarbons

\begin{tabular}{|c|c|c|c|c|c|c|c|c|c|c|}
\hline \multirow{2}{*}{ Nozzle number } & \multicolumn{10}{|c|}{ Test fluid number } \\
\hline & a 1 & 2 & 3 & 4 & 5 & b 1 & 2 & 3 & 4 & 5 \\
\hline $1 \ldots$ & 38.97 & 36.67 & 38.47 & 36.90 & 37.97 & 62.45 & 58.10 & 62.10 & 59.00 & 60.65 \\
\hline $2 \ldots$ & 40.00 & 38.45 & 39.50 & 39.40 & 39.00 & 65.50 & 61.20 & 63.80 & 63.25 & 63.35 \\
\hline $3 \ldots$ & 40.14 & 37.65 & 39.97 & 38.57 & 39.32 & 64.12 & 60.05 & 65.30 & 61.50 & 62.00 \\
\hline $4 \ldots$ & 40.26 & 38.20 & 39.92 & 38.80 & 38.95 & 65.45 & 61.50 & 64.25 & 62.70 & 62.70 \\
\hline $5 \ldots \ldots$ & 41.30 & 38.62 & 40.93 & 40.02 & 40.06 & 66.85 & 61.25 & 66.60 & 63.50 & 64. 20 \\
\hline $6 \ldots$ & 41.52 & 39.00 & 41.80 & 40.41 & 40.45 & 66.85 & 62.65 & 67.25 & 64.65 & 64.55 \\
\hline $7 \ldots$ & 41.57 & 39.80 & 40.27 & 40.67 & 40.35 & 67.45 & 63.75 & 66.50 & 66.00 & 64.70 \\
\hline $8 \ldots$ & 41.57 & 38.37 & 41. 46 & 39.57 & 40.12 & 66.05 & 61.70 & 67.25 & 63.45 & 63.45 \\
\hline 9 & 41.63 & 38.82 & 40.45 & 41.13 & 39.95 & 66.85 & 61.05 & 66.50 & 64.95 & 64.35 \\
\hline $10 \ldots \ldots$ & 42.07 & 39.05 & 41.10 & 40.55 & 40. 70 & 67.30 & 62.10 & 67.60 & 64.60 & 65.10 \\
\hline $11 \ldots$ & 42.34 & 41.39 & 41.47 & 41.93 & 41. 25 & 69.45 & 66.00 & 67.00 & 67.35 & 66. 70 \\
\hline $12 \ldots$ & 42.40 & 39.52 & 41.47 & 41. 16 & 40.75 & 67.55 & 62.85 & 67.95 & 65.15 & 64.85 \\
\hline $13 \ldots$ & 42.44 & 40.03 & 42.17 & 41.73 & 40.95 & 69.05 & 63.85 & 68.15 & 66.15 & 66.20 \\
\hline $14 \ldots$ & 42.60 & 40.33 & 41.98 & 41.42 & 40.74 & 69.20 & $6 \therefore 30$ & 67.90 & 65.85 & 65.85 \\
\hline $15 \ldots$ & 42.64 & 40.42 & 42.34 & 41.92 & 41.87 & 69. 28 & 63.70 & 68.75 & 66.15 & 66.65 \\
\hline 16 & 42.67 & 39.92 & 42.64 & 41.30 & 41. 22 & 68.55 & 63.60 & 68.85 & 65.90 & 65.85 \\
\hline $17 \ldots$ & 43.16 & 41.00 & 43.82 & 42.12 & 41.73 & 70.10 & 65.80 & 70.10 & 67.55 & 67.30 \\
\hline $18 \ldots$ & 43.67 & 40.77 & 42. 92 & 42. 13 & 41.86 & 69.65 & 65. 25 & 69.80 & 67.35 & 67.05 \\
\hline $19 \ldots$ & 44.02 & 40.87 & 42.53 & 42.54 & 42.45 & 70.50 & 64.55 & 70.30 & 67.00 & 67.90 \\
\hline $20 \ldots$ & 44.73 & 41.37 & 43.87 & 42.83 & 42. 77 & 71.10 & 65. 70 & 71.60 & 68.05 & 68.45 \\
\hline 21. & 45.07 & 41.05 & 43. 20 & 43. 64 & 43.87 & 72.08 & 66.30 & 72.00 & 68.90 & 69.80 \\
\hline $22 \ldots$ & 45. 20 & 42.08 & 43. 72 & 43.59 & 43.03 & 71.85 & 66.10 & 70.60 & 68.55 & 69.40 \\
\hline $23 \ldots$ & 45.53 & 42.57 & 45. 13 & 43.90 & 44. 20 & 72.73 & 68.05 & 73.65 & 70.45 & 70.05 \\
\hline $24 \ldots$ & 45.66 & 41.83 & 43.97 & 44.45 & 43.97 & 72.05 & 66.85 & 72.95 & 70.50 & 71.20 \\
\hline $25 \ldots \ldots \ldots$ & 46.10 & 42.43 & 44. 13 & 44. 48 & 44.64 & 72.60 & 65.80 & 73.45 & 68.50 & 70.90 \\
\hline $26 \ldots$ & 47.60 & 45.07 & 45.83 & 46.42 & 45. 79 & 76.88 & 71.30 & 76.00 & 73.45 & 74.10 \\
\hline
\end{tabular}

a Test pressure in first five columns is $98 \mathrm{lb} / \mathrm{in}^{2}$.

b Test pressure in last five columns is $250 \mathrm{lb} / \mathrm{in}^{2}$.

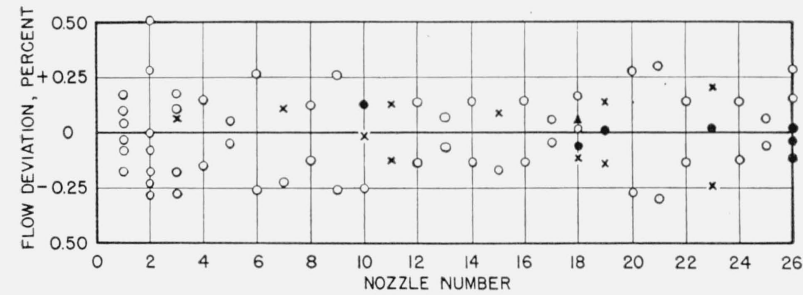

Figure 8. Nozzle flow reproducibility with Varsol at 98 psig after cleaning. Number of identical readings: $\bigcirc$, one; $x$, two;

$$
\text { - three; } \mathbf{\Delta} \text {, five. }
$$

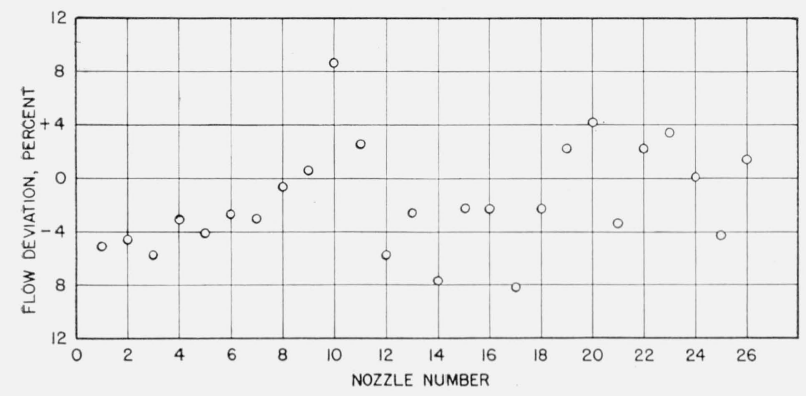

Figure 9. Comparison of flows before and after cleaning nozzles, Varsol at 98 psig.

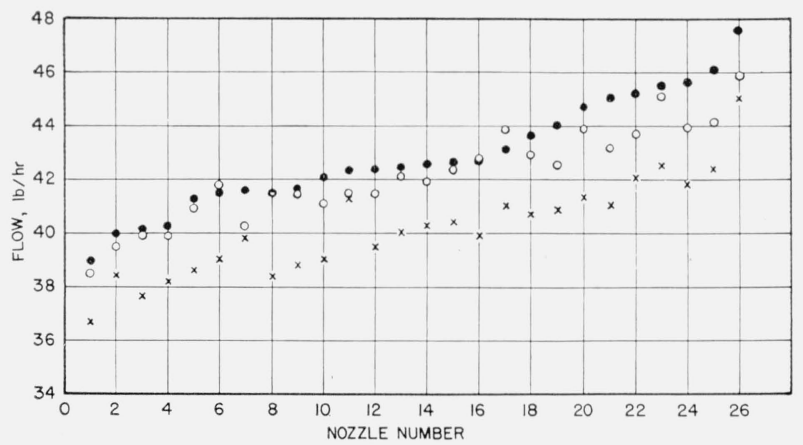

Figure 10. Flow of 26 cleaned nozzles at 98 psig.

O, Apco; $\bullet$ Varsol; x, $n$-heptane.

the changes in flow ranged from +8 to -8 percent, and only three of the 26 nozzles changed less than 1 percent.

The data of table 1 for Varsol, Apco, and $n$-heptane at a pressure of $98 \mathrm{lb} / \mathrm{in}^{2}$ are compared in figure 10. The nozzles were numbered arbitrarily in the order of increasing flow with Varsol, so that a relatively smooth curve is obtained for this fluid. However the corresponding curves for the other 
two fluids are not smooth, indicating that nozzles matched for one fluid are not necessarily matched for fluids having different properties, and showing the need for caution in selecting a standard test fluid.

To further emphasize this point, consider the example furnished by nozzles $6,7,8$, and 9 . With Varsol these nozzles show an average flow of 41.57 $\mathrm{lb} / \mathrm{hr}$ and a total spread of 0.25 percent. With $n$-heptane the order is different, the average flow 6.2 percent lower, and the spread is 3.7 percent. With Apco the flows are in a still different order, the average flow is 1.4 percent lower, and the spread is 3.7 percent. There are many other similar examples in the data of figure 10.

From the data of table 1 , the ratio of the flow at $250 \mathrm{lb} / \mathrm{in}^{2}{ }^{2}$ to that at $98 \mathrm{lb} / \mathrm{in}^{2}{ }^{2}$ can be calculated for each nozzle and for each test fluid. For fluids No. 1, 2, and 3 this observed ratio is as follows:

Varsol, ranging from 157 to 164 percent, averaging 160.2 percent; $n$-heptane, ranging from 156 to 161 percent, averaging 158.7 percent; and Apco, ranging from 160 to 167 percent, averaging 163.2 percent.

As a further illustration, the ratios are plotted in figure 11 in the form of a frequency curve with

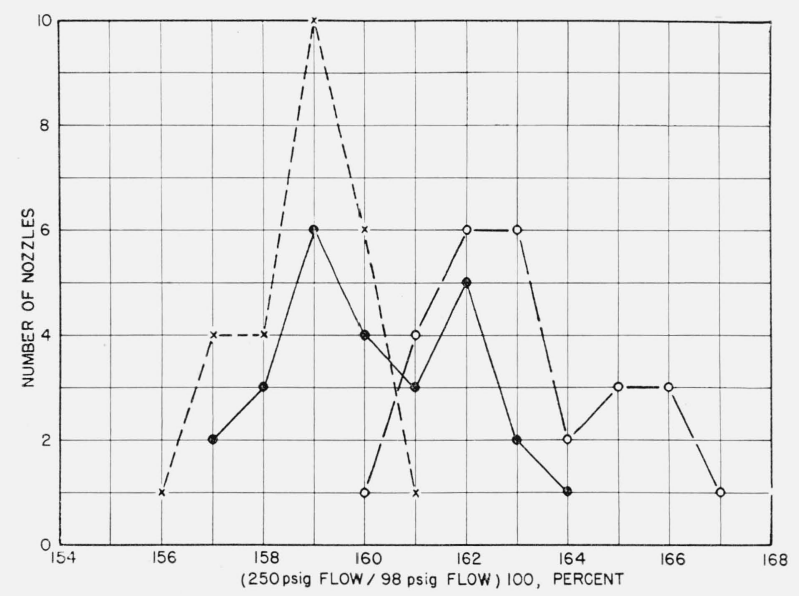

Figure 11. $\frac{250 \mathrm{psig}}{98 \mathrm{psig}}$ flow ratio with different hydrocarbons - -, Apco;---, Varsol; - - -, $\eta$-heptane.

each point showing the number of nozzles haring a given ratio. It will be apparent from these results that the characteristics of the test fluid must be known before the ratio can be specified.

As stated previously, fluids No. 4 and 5 have the same density and were chosen to show the effects of viscosity on nozzle performance. Figure 12 shows how the results obtained with Soltrol varied from those obtained with the mixture of isooctanes. It is at once apparent that the effect of viscosity varies in both magnitude and direction from nozzle to nozzle. Hence it does not seem possible to develop any means of correcting for the viscosity of the test fluid.

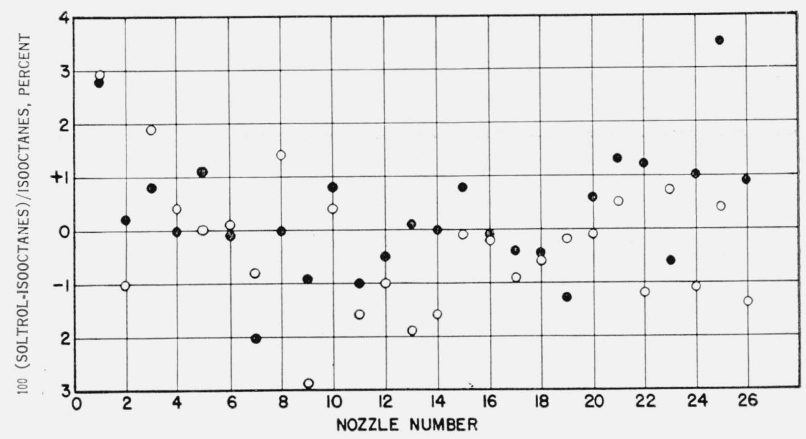

Figure 12. Viscosity effect on spray nozzles. O. $98 \mathrm{psig} ; \mathbf{0}, 250$ psig.

\section{Flow Tests With Air}

Early in this nozzle test program it appeared desirable to attempt the development of equipment using air instead of a flammable hydrocarbon as a test fluid. Such development seemed a logical extension of the previous successful evolution of the Navy Orifice Comparator, in which air is used to flow-test metering jets of aircraft carburetors with greater speed, accuracy, and safety than could be attained by other methods.

In applying the method to spray nozzles, the apparatus shown diagrammatically in figure 13 was investigated. Briefly, air compressed to $50 \mathrm{lb} / \mathrm{in}^{2}{ }^{2}$ or more is passed through a pressure regulator and a filter to a test fixture consisting essentially of two chambers, each about $1 \frac{1 / 4}{4}$ in. in diameter by $4 \mathrm{in}$. in length, separated by a small orifice or bleed. The second chamber serves as a mounting for the nozzle, through which all of the regulated air escapes to the atmosphere. Pressure taps and manometers provide for observing the pressure in the second chamber and the drop in pressure between the two chambers.

In operation, the pressure in the second chamber is held constant, which means that the drop in pressure across the nozzle is also constant, and the drop in pressure across the bleed between the two chambers is observed. The latter is determined by 


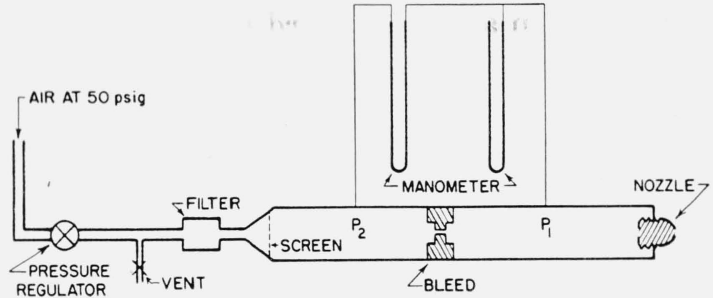

FIgURE 13. Schematic diagram of nozzle air test.

the volume rate of flow between chambers, which, in turn, is a function of the flow characteristics of the test nozzle.

Obviously the method is comparative rather than absolute, so that a set of nozzles calibrated by some other method is required for the calibration of the equipment using air. For nozzles having a flow capacity in the range 40 to $50 \mathrm{lb} / \mathrm{hr}$ at 100 $\mathrm{lb} / \mathrm{in}^{2}{ }^{2}$, it has been found by experiment that the air-test method gives best results when the bleed between the two chambers consists of a single hole made by a No. 76 drill (diameter $=0.019$ in.), and when the pressure in the second chamber is from 1.2 to 2 times the pressure drop across the bleed.

In developing the air-test method, the 26 nozzles mentioned previously were tested with various constant pressures in the second chamber throughout the range from $10 \mathrm{in}$. of water to 50 in. of mercury. The best correlation between results with air and with liquid hydrocarbons is obtained in the range 25 to $35 \mathrm{in}$. of mercury. An example of this correlation is given in figure 14 , in which the pressure in the second chamber $\left(P_{1}\right)$ was $30 \mathrm{in.} \mathrm{of} \mathrm{mercury,} \mathrm{and} \mathrm{the} \mathrm{observed} \mathrm{drop}$ in pressure across the bleed $\left(P_{2}-P_{1}\right)$ is plotted against the observed flow of Varsol at a pressure of $98 \mathrm{lb} / \mathrm{in}^{2}$. The best smooth curve through the observed points seems to be a straight line, from which the maximum deviation is less than 2 percent and the average deviation is less than 1 percent. The sensitivity of this air apparatus was about $1 \mathrm{in}$. of mercury per pound of fuel discharged through the nozzle per hour.

The dashed lines in figure 14 are the limits of flow specified for nozzles coded red, green, and purple. On the basis of the results shown in this figure it might be concluded that the air-test method was satisfactory for flow-testing spray nozzles. If this were true, it is certainly to be preferred from the standpoint of speed and safety.

As already stated, figure 14 compares the results obtained with air and those obtained with
Varsol. Similarly figure 15 shows a comparison of results with air and Apco, and figure 16 shows a comparison of those with air and $n$-heptane, all data for liquid fuels being for a pressure of 98 $\mathrm{lb} / \mathrm{in}^{2}$. Deviations from the straight lines are all within \pm 3 percent except for one nozzle in figure 16. Considering that the nozzles do not perform consistently with the three liquid test fluids, as was shown in figure 10, the correlation of the results with air and those with liquids is better than might have been expected.

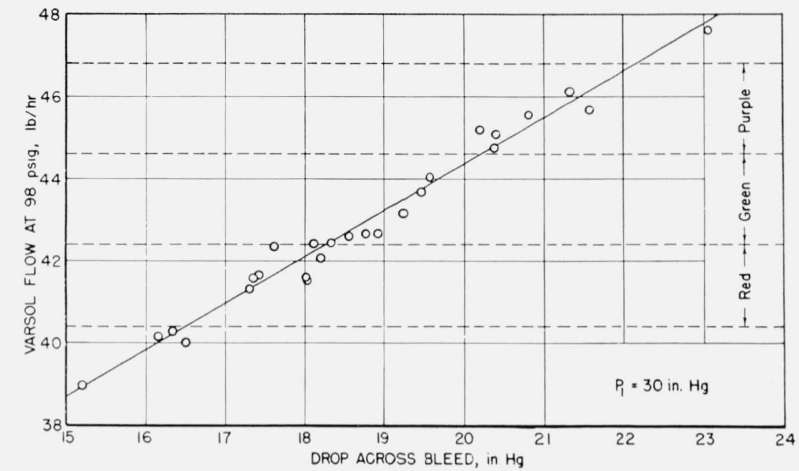

Figure 14. Correlation of nozzle tests with air and Yarsol.

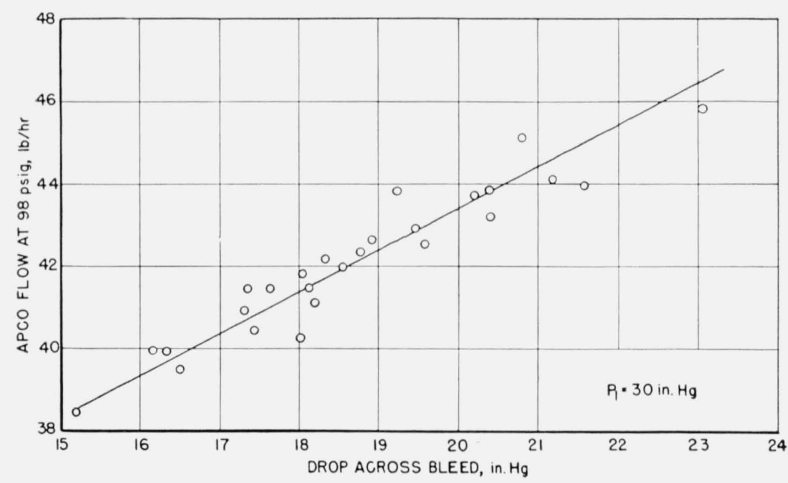

Figure 15. Correlation of nozzle tests with air and Apco.

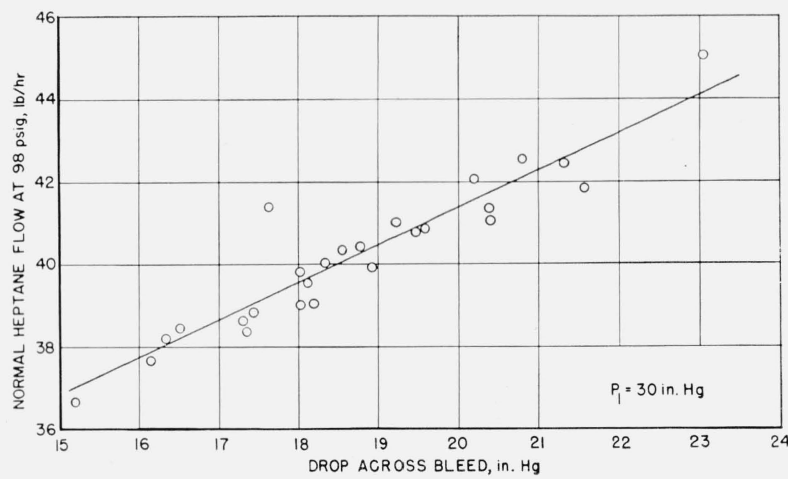

Figure 16. Correlation of nozzle tests with air and normal heptane. 
In its present state, the air-test method would seem to have considerable merit for preliminary tests of nozzles, particularly in production and after overhaul. It would certainly be valuable in rejecting nozzles that flow so far from the design value that tests with liquid would be a waste of time, and in grouping nozzles within reasonably narrow flow limits. It might also be useful in the matching of nozzle bodies and inserts to get desired performance.

As a matter of fact, the uncertainties in the performance of nozzles determined with air are probably little, if any, greater than the present uncertainties in the actual performance of nozzles in engines. Consequently the further development of the air-test method will be carried along as rapidly as the resolution of the over-all problem of nozzle performance seems to warrant.

\section{Discussion and Conclusions}

The nozzles used in these tests were received late in 1947, and are believed typical of nozzles of this type in production at that time. The presence of chips, burrs, and inadequate finish on certain parts were pointed out months ago, and it seems probable that such easily remedied faults may no longer be a matter of concern.

A fixed nozzle performs two important functions, namely the production of a spray and the metering of fuel. This report deals only with fuel metering. In nozzles of the type tested, this is accomplished primarily at two locations within the nozzle. These are at the four tangential slits that operate in parallel, and at the discharge orifice in the nozzle body, which is in series with the four slits. It is not surprising, therefore, that the simple law of discharge through an orifice does not hold exactly for the nozzle as a whole. As examples, the relation between pressure and flow for one nozzle may differ somewhat from that of another, and the effect of a given change in viscosity of the test fluid may be in one direction for one nozzle and in the opposite direction for another.

Examined from this point of view, it is surprising that the results obtained with six different test fluids including air agree as well as they do.

Perhaps the most obvious conclusion from these studies involves the choice of a fluid suitable for testing fuel nozzles and other engine auxiliaries.
It is believed that a fluid chosen as a standard for this purpose should have as many of the following characteristics as may be found attainable:

(a) It should be cheap and free from highly strategic ingredients; (b) It should be available in quantity from many sources, and its physical properties should be readily reproducible from a production standpoint; (c) It should be safe, noncorrosive, and should have the same effects as engine fuels on packings, diaphragms, etc.; (d) Its physical properties should be the same as those of engine fuels and should not change with use by evaporation of light ends; (e) When exceptions are made to the above requirements, it must be possible to interpret data obtained with the test fluid in terms of performance in engines.

If the test fluid differs in density and/or viscosity from the fuel used in the engine, the present results show that:

(a) The actual rate of fuel delivery to the engine at any pressure may differ by several percent from the rate predicted from the test data; (b) Nozzles matched for the test fluid at a particular pressure may not be matched at this or any other pressure in the engine; and (c) it will not be practicable to develop corrections which are generally applicable for differences between physical properties of the test fluid and the engine fuel.

Both density and viscosity of the fuel being metered by a nozzle are important in determining. its rate of discharge at a given pressure. Both those properties change considerably with temperature. Thus it seems likely that turbo-jet operation might be improved by giving more attention to the temperature of the fuel entering the individual nozzles, and to possible methods for its control.

Much additional thought and experimentation are warranted in the development of nozzle test data that will be truly indicative of the performance of nozzles in operating engines. Even though some fluid is selected as a standard for test purposes, there remains the development of satisfactory test methods and the evolution of significant test specifications. An obvious first step toward the latter is the determination of tolerances in flow that can be allowed in engines, and more particularly of the unavoidable differences encountered in operating engines.

Thus the over-all problem of determining, by means of bench tests, whether a given set of spray 
nozzles will give optimum performance in an engine is highly complex. Equally difficult is the testing of a set of replacement nozzles so there will be no question that they will perform as well as the original set.

So long as spray nozzles are used in engines, there is no doubt that solution of the aforementioned problems will pay dividends in improved engine performance, particularly at high altitudes. Employment of spray nozzles requires that the general level of fuel pressure be high, which in turn involves mechanical difficulties with fuel pumps, lines, manifolds, and seals, and increases the fire hazard in case a fuel line is broken. It, therefore, seems legitimate to raise a question as to the relative merits of expending research effort on the further development of the various components of high-pressure fuel systems, or on the development of combustion chambers that will function with low-pressure fuel and without spray nozzles.

Washington, January 10, 1949. 